\title{
Intervenciones multifactoriales para pacientes con diabetes tipo 2
}

\author{
Multifactorial intervention for type 2 diabetes
}

Gæde y col. The New England Journal of Medicine; 2008; 358:580-591.

\section{Objetivo}

Evaluar si una intervención intensiva y multifactorial (IIM) tiene algún efecto sobre la mortalidad global y/o cardiovascular (CV) en diabéticos tipo 2 con microalbuminuria.

\section{Diseño, lugar y pacientes}

Seguimiento durante 5,5 años de una cohorte dinamarquesa de pacientes diabéticos tipo 2 con microalbuminuria posterior al estudio Steno 2, un ensayo clínico aleatorizado abierto que había demostrado que una IIM disminuye a la mitad el riesgo de enfermedad CV y microvascular; luego de haberla comparado con el "tratamiento convencional" de aquel momento histórico. En el estudio original los 160 individuos habían sido aleatorizados a dos grupos: 80 recibieron un "tratamiento convencional" acorde a la guía de la Asociación Médica Danesa de 1980 y en los 80 restantes se fijaron metas más estrictas para los niveles de glucemia, lípidos y tensión arterial, completando un período de intervención de 7,8 años.

\section{Intervención}

El grupo aleatorizado a IIM recibió atención en una clínica especializada en diabetes, donde se propuso un esquema escalonado de cambios del estilo de vida (dieta, ejercicio y cese del tabaquismo). Si no se lograban las metas, se agregaba metformina o glicazida, ambas o se insulinizaba al paciente con insulina NPH para alcanzar un $\mathrm{Hb}$ glicosilada menor igual a $7 \%$. Se utilizaron inhibidores de la enzima convertidora de angiotensina (IECA) o antagonistas del receptor de angiotensina II (ARA II) para alcanzar el control de la tensión arterial; y estatinas o fibratos para obtener los niveles deseados de colesterol total y triglicéridos.

\section{Medición de resultados principales}

Mortalidad por cualquier causa y CV (accidente cerebrovascular, amputación por isquemia, cirugía vascular periférica y/o revascularización coronaria).

\section{Resultados}

Se resumen en la tabla 1.

Tabla 1: resultados de una intervención intensiva multifactorial en pacientes con diabetes tipo 2 con microalbuminuria.

\begin{tabular}{|c|c|c|c|c|}
\hline $\begin{array}{l}\text { Resultados a los } \\
13 \text { aníos de } \\
\text { seguimiento }\end{array}$ & $\begin{array}{l}\text { Tratamiento } \\
\text { convencional } \\
\text { ( } \mathrm{n}=80) \text { y } \%\end{array}$ & $\begin{array}{c}\text { Intervención } \\
\text { intensiva } \\
\text { multifactorial } \\
(n=80) \text { y } \%\end{array}$ & Hazard ratio* & NNT \\
\hline $\begin{array}{l}\text { Muertes por } \\
\text { cualquier causa }\end{array}$ & $\begin{array}{|ll|}40 & (50 \%) \\
\end{array}$ & $24 \quad(30 \%)$ & $0.54 \quad(0,32$ a 0,89$)$ & 5 (3 a 20) \\
\hline $\begin{array}{l}\text { Muertes de causa } \\
\text { cardiovascular }\end{array}$ & $\begin{array}{|ll|}19 & (24 \%) \\
\end{array}$ & $9 \quad(11 \%)$ & $0,43(0,19$ a 0,94$)$ & $8(5$ a 67$)$ \\
\hline
\end{tabular}

NNT: número de pacientes que es necesario someter durante 13 años a una intervención intensiva multifactorial para evitar un evento.

\section{Conclusiones}

Luego de 13,3 años (7,8 años de tratamiento intensivo y 5,5 años de seguimiento) hubo una reducción de un $20 \%$ del riesgo absoluto de muerte por cualquier causa en diabéticos tipo II con microalbuminuria en aquellos pacientes sometidos a una IIM que recibieron un tratamiento intensivo, mientras que, con respecto a las muertes por eventos cardiovasculares, la reducción del riesgo absoluto fue de un $12,45 \%$.

Palabras clave: mortalidad, mortalidad cardiovascular, diabéticos con microalbuminuria.

Key words: mortality, cardiovascular mortality, diabetes and microalbuminuria Fuente de financiamiento: Danish Health Research Council.

Ver glosario*

\section{Comentario}

Este estudio muestra un $20 \%$ de reducción en el riesgo absoluto de mortalidad en diabéticos de alto riesgo cardiovascular al realizar un tratamiento multifactorial e intensivo con metas estrictas. Durante la etapa de seguimiento disminuyeron las diferencias en los factores de riesgo de ambos grupos, ya que se instauró el tratamiento intensivo en el grupo que originalmente había sido asignado a "tratamiento convencional". Sin embargo, aquellos individuos que recibieron en forma más temprana el tratamiento intensivo, tuvieron menos muertes de orígen CV y por cualquier causa. Esta suerte de efecto "dosis-respuesta" -a mayor precocidad de la intervención, mayor beneficio atribuible* a la misma- respalda los beneficios de este tipo de IMM instaurada desde etapas tempranas de la enfermedad.

En este sentido, no podemos evitar la comparación con una investigación fundacional, el ensayo clínico de control de la diabetes tipo 1 y sus complicaciones $\left(\mathrm{DCCT}^{1}\right)$ y su posterior cohorte en la que luego de los primeros resultados, ambos grupos recibieron la intervención intensiva. Luego de un total de 17 años de seguimiento, la reducción del riesgo de sufrir eventos CV atribuible* al tratamiento intensificado de insulina fue de $2,8 \%$. Respecto del peso de cada componente por separado y luego de más de siete años de seguimiento, el estudio prospectivo británico de diabetes ${ }^{2}$ (UKPDS) concluyó que las estatinas y los antihipertensivos serían las drogas con mayor beneficio para reducir el riesgo $\mathrm{CV}$, seguidas por los hipoglucemiantes orales y la aspirina.

\section{Conclusiones de la comentadora}

Si bien este estudio no permite establecer qué elementos de la IIM contribuyen más a la reducción del riesgo de sufrir eventos $\mathrm{CV}$, tiene la fortaleza de una década de seguimiento y sí permite observar los beneficios del tratamiento simultáneo de los diferentes factores de riesgo, como recomiendan las actuales guías de tratamiento de esta entidad clínica ${ }^{3}$.

Gabriela Buela [ Servicio de Medicina Familiar y Comunitaria del Hospital Italiano de Buenos Aires. gabriela.buela@ hospitalitaliano.org.ar ]

Buela G. Intervenciones multifactoriales para pacientes con diabetes tipo 2. Evid. actual. práct. ambul; 11(5): 136 Sep-Oct.2008. Comentado de: G Gæde P y col. Effect of a Multifactorial Intervention on Mortality in Type 2 Diabetes. The New England Journal of Medicine, 2008; 358:580591. PMID: 18256393. Disponible en URL: http://content.nejm.org/cgi/content/short/358/6/580 (último acceso 06/06/08).

\section{Referencia}

1. Diabetes Control and Complications Trial Research Group. The effect of intensive treatment of diabetes on the development and progression of long-term complications in insulin-dependent diabetes mellitus. N Engl J Med 1993;329:977-86.

2. Holman R y col. Long-Term Follow-up after Tight Control of Blood Pressure in Type 2 Diabetes. N Engl J Med 2008;359. Disponible en URL:

http://content.nejm.org/cgi/reprint/NEJMoa0806359v1.pdf (último acceso 21/10/08).

3. National Collaborating Centre for Chronic Conditions. Type 2 diabetes: national clinical guideline for management in primary and secondary care (update). London: Royal College of Physicians, 2008. Disponible en URL: http://www.nice.org.uk/guidance/index.jsp?action=download\&o=40803 (último acceso 11/06/08). 